See discussions, stats, and author profiles for this publication at: https://www.researchgate.net/publication/286759976

\title{
A low-cost control system for BLDC motors applied to teaching
}

Conference Paper · June 2014

DOI: 10.1109/TAEE.2014.6900164

CITATION

1

4 authors, including:

$\sqrt{75}$

Himar Fabelo

Universidad de Las Palmas de Gran Canaria

52 PUBLICATIONS 424 CITATIONS

SEE PROFILE

Some of the authors of this publication are also working on these related projects:

Project UAV design optimzation View project

[Helicoid] Hyperspectral imaging for brain cancer detection View project
Jose Maria Cabrera

Universidad de Las Palmas de Gran Canaria

7 PUBLICATIONS 4 CITATIONS

SEE PROFILE 


\title{
A Low-Cost Control System for BLDC Motors Applied to Teaching
}

\author{
Himar A. Fabelo, Aurelio Vega, José Cabrera, Víctor Déniz \\ Dept. of Electronics Engineering and Automatics (DIEA) \\ Institute for Applied Microelectronics (IUMA) \\ University of Las Palmas de Gran Canaria (ULPGC), Spain \\ hfabelo@iuma.ulpgc.es, avega@iuma.ulpgc.es, jose.cabrera@ulpgc.es, vdgonzalez@iuma.ulpgc.es
}

\begin{abstract}
In this paper, the process carried out to design and manufacture the hardware of a low-cost control system for brushless direct current motors based on a ATmega64M1 is described. The proposed control system, applied to teaching, consists of the controller presented in this paper and a $\mathrm{C}$ library specially created for this project. Three types of different control systems are detailed. The first is the basic system, which can be used for teaching microcontroller programming within the scope of brushless motors. The second system presented is used to monitor and manage electric vehicles powered by a 6-phase brushless motor. This system offers the possibility to be used as a practice teaching module for electromechanical students. Finally, we detail a system that enables the control of remotely operated vehicles. This configuration can also be oriented to the control of any type of robotic vehicle powered by brushless motors. These three systems use the controller proposed in this article. The difference between them is the number of controllers that are required for their operation and how the system components are interconnected.
\end{abstract}

Keywords- brushless direct current motor (BLDCM), BLDC control system, electric vehicle control system, remotely operated vehicle control system.

\section{INTRODUCTION}

BLDC motors (Brushless Direct Current Motors) have excellent torque characteristics, high performance, and a very wide range of speeds, plus a lifetime. They have no brushes switching, so the need for periodic maintenance is reduced. However, the use of a complex control system based on a $\mu \mathrm{C}$ (microcontroller) that manages the switching of the motor coils is necessary.

Nowadays, these motors are a viable alternative to traditional DC (Direct Current Motors) motors in almost any application. BLDC motors are used in industries such as automotive, aerospace, consumer electronics, medical, automation equipment and instrumentation, etc.

This project has focused primarily on applications for electric or hybrid cars, electric motorcycles, ROVs (Remotely Operated Vehicles) and similar applications within the field of robotics.

For the reasons given above and the degree of complexity of these new systems versus traditional systems of DC motors, students of electronics, electromechanical and robotics should know the features and operation of the control systems for BLDC motors. With a broad base of knowledge in this field, they may confront the working world in the coming years in the above sectors.

\section{THE CONTROLlER}

The BLDCM controller design is based on $\mu \mathrm{C}$ ATmega64M1 [1], which, by its characteristics is suitable for the control of this type of motors. The main features of this $\mu \mathrm{C}$ that are required for this project are as follows:

- An 8-bit AVR CPU.

- Up to 11 single ended channels 10-bit ADC (Analog to Digital Converter), one of which will be used to capture the analog signal from the speed adjustment potentiometer.

- A CAN (Controller Area Network) and RS-232 (Recommended Standard 232) interfaces used to carry out the communication between the controller and the testing and monitoring computer.

- A 12-bit high speed PSC (Power Stage Controller) module. This module controls the power stage and the switching of the BLDC motor coil signals by the technique of PWM (Pulse Width Modulation) [2][3][4].

\section{A. Controller Design}

The main stages in the design of the controller are three: the control stage, the communication stage and the power stage. At the control stage the configurations of the inputs and outputs of the $\mu \mathrm{C}$ are performed. In the communication stage, it is located the electronics used to interconnect the $\mu \mathrm{C}$ with the $\mathrm{PC}$. Finally, in the power stage, they are located the drivers that raise the output voltage of the PSC module of the $\mu \mathrm{C}$ to get the right voltage for activating the MOSFET transistors. These transistors excite the motor coils with the correct voltage.

Fig. 1 shows the different modules of the controller's design. 


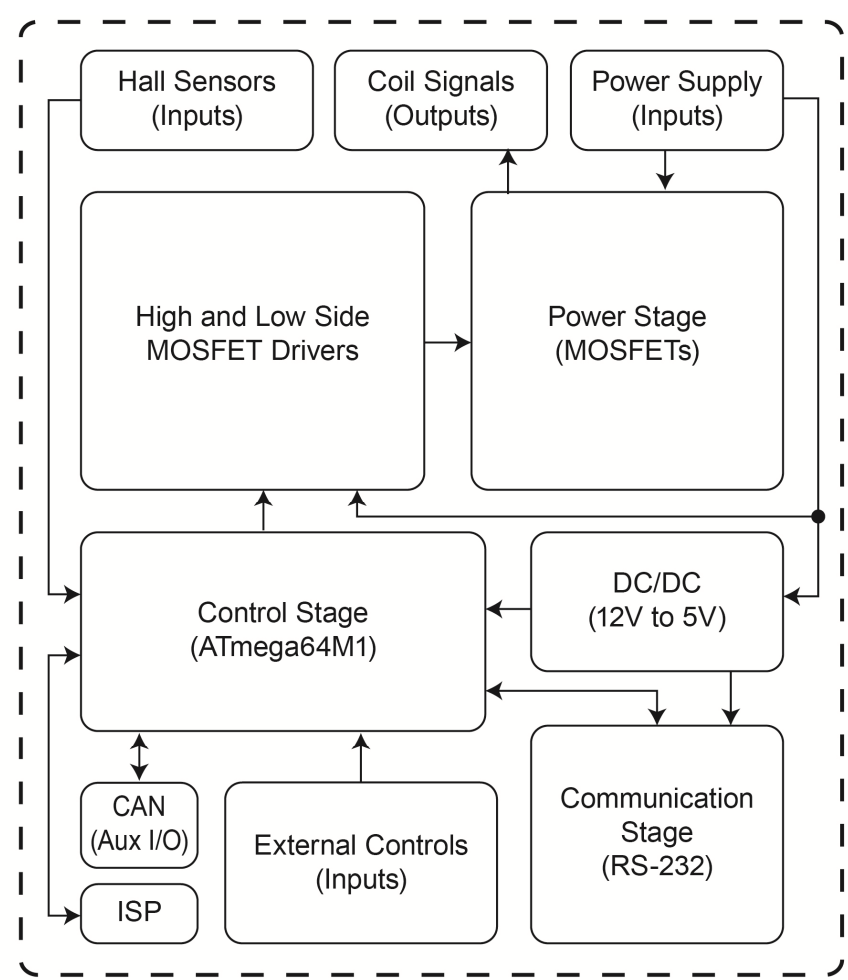

Fig. 1. Diagram of the parts of BLDCM controller

\section{1) Control stage}

In the control stage it is located one of the most important elements of the system: the $\mu \mathrm{C}$ ATmega64M1. It reads the values obtained from the Hall sensors of the BLDC motor. These sensors determine the position of the rotor. By reading these values, the $\mu \mathrm{C}$ generates a PWM signals with a frequency of $16 \mathrm{kHz}$ and a peak voltage of $5 \mathrm{~V}$. The PWM signals are sent to the drivers of the MOSFETs, located in the power stage, phase-shifted $120^{\circ}$ from each other. This offset is established by the signals of the Hall sensors (Fig. 2).

\section{2) Power stage}

At this stage the MOSFET drivers are located. These drivers are supplied with a voltage of $12 \mathrm{~V}$ and raise the voltage of the PWM signals generated by the $\mu \mathrm{C}$ to that value. These signals attack the gates of the power MOSFET (IRFP4568), so that the supply voltage (Vcc) can pass to the BLDC motor. The voltage and the current that flow through the MOSFETs, according to the switching logic set up by the $\mu \mathrm{C}$, excites the motor coils causing the motor rotate. The duty cycle of the PWM signals, set up by the speed adjust potentiometer, determine the speed of the motor.

Fig. 3 shows one of the three parts of this power stage. The motor coil can be found in 3 different states caused by the high/low driver signals:

- VCC: coil is connected to the supply voltage.

- GND: coil is connected to the ground.

- NC: coil is not connected.
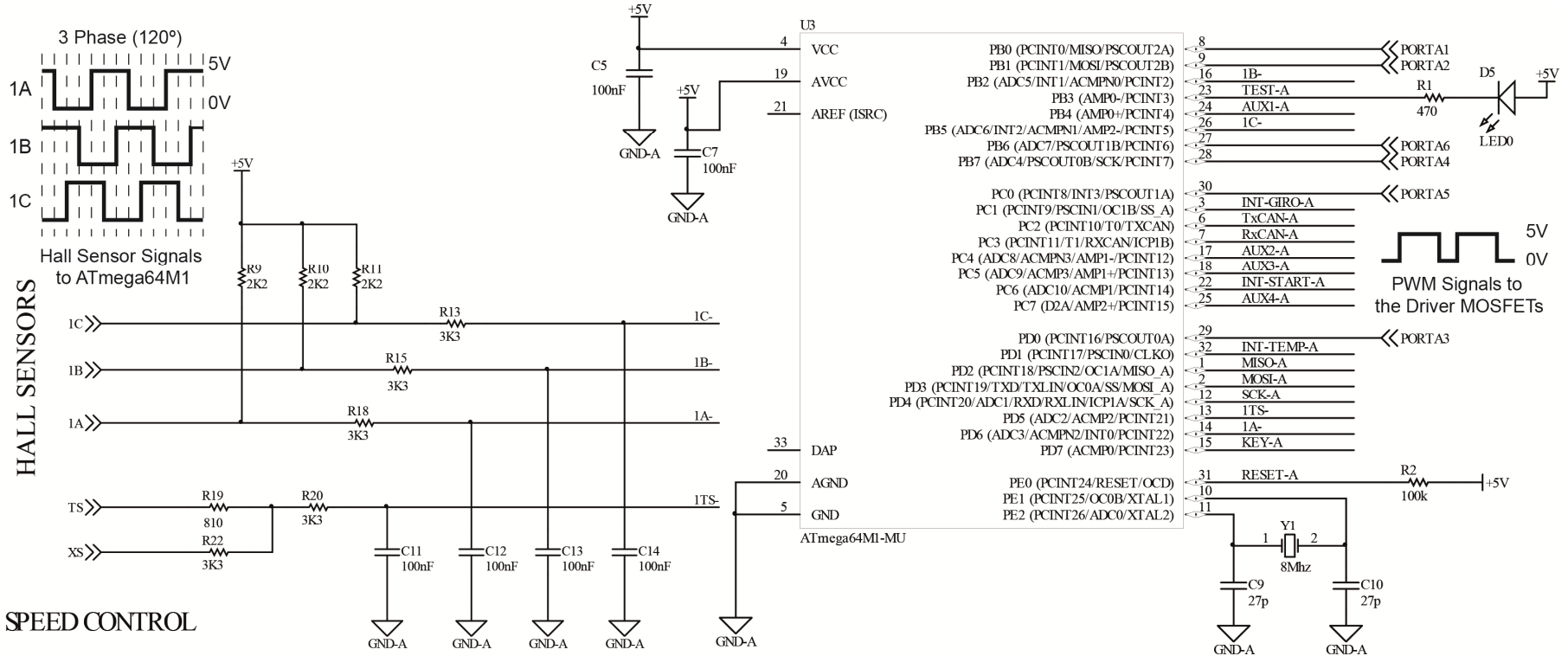

Fig. 2. Control stage of the BLDC controller 


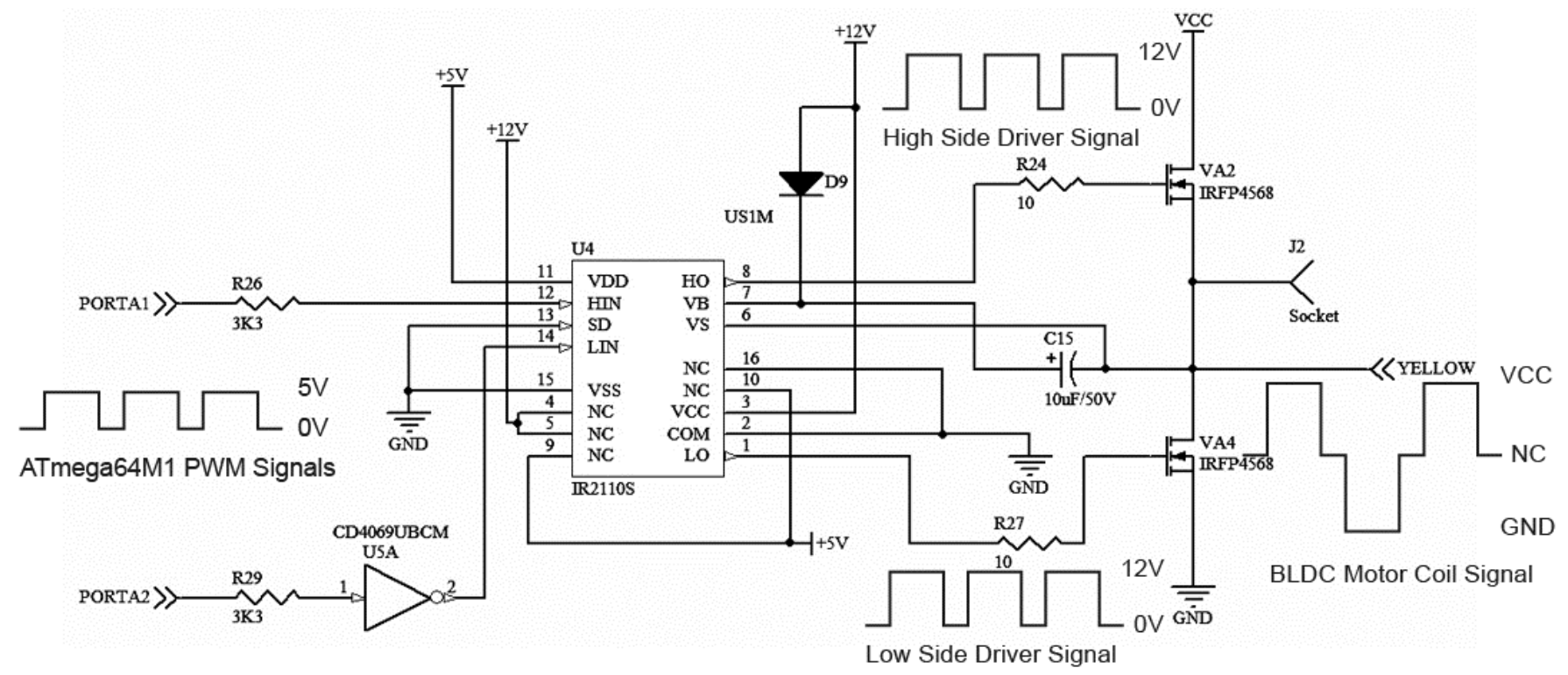

Fig. 3. One of the three parts of the power stage

\section{3) Communication stage}

On the other hand, the design of the controller has a communication stage in which the controller is connected to a workstation (PC or display) via a serial communication (RS232). In addition, the $\mu C$ enables to make this connection through the CAN protocol (Controller Area Network), which ensures greater security and robustness against interferences and collisions in data transmission. This is why, so we decide to have the possibility of also using this protocol.

Finally, at this stage note the part where the connections of external controls and sensors for the controller are performed. These controls and sensors may be:

- The ignition switch of the system.

- The motor speed adjustment potentiometer.

- The motor rotation direction switch.

- The motor temperature sensor.

In addition, the ISP (In-System Programming) connector is located in an accessible way to carry out the $\mu \mathrm{C}$ programming with the $\mathrm{C}$ library that has been developed to control this type of motors [5]. In this process, it is used the free software provided by the manufacturer of the $\mu \mathrm{C}$ (Atmel) from their website, the Atmel Studio 6.0 [6]. The programming of the $\mu \mathrm{C}$ is performed using this software and the AVRISP mkII programmer device [7] through the ISP interface.

\section{B. Design and Manufacture of the PCB}

The design and the manufacture of the PCB (Printed Circuit Board) controller have been performed at the ULPGC-IUMASFP Laboratory (Prototype Manufacturing Service of the Institute for Applied Microelectronics at the University of Las Palmas de Gran Canaria). We used the simple Eurocard format $(100 \mathrm{~mm} \times 160 \mathrm{~mm})$, so that the controller can be connected in standard racks.
The PCB controller was designed using the Altium Designer software [8]. This is a 2-layer design with the component mounting in the top layer. Fig. 4 shows a 3D view of the final design of the prototype, developed under the simple Eurocard format. Likewise, to manufacture the PCB, a set of files known as Gerber Files are generated from the software (Fig. 5). These files are used to print the photolithos of each layer, in addition to the files used to drill the plate and to manufacture the solder mask.

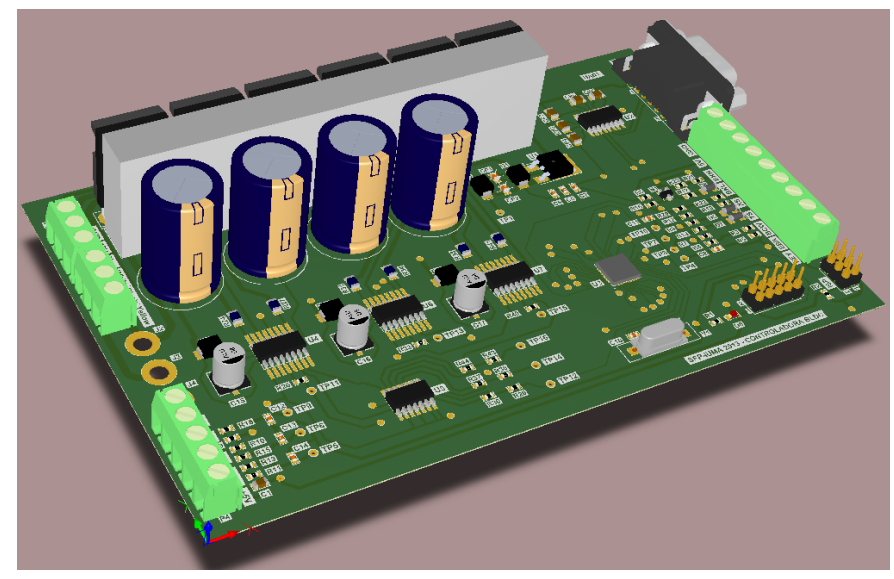

Fig. 4. 3D view of the BLDCM controller

Once the PCB manufacturing process is completed, the manually placement of the SMD (Surface Mount Devices) components is performed. This process is carried out by applying solder paste on the surface mount PADs of the components using a spatula. In order to apply the paste correctly, a welding screen is used. Subsequently, SMD components are placed using a manual Pick \& Place machine. 


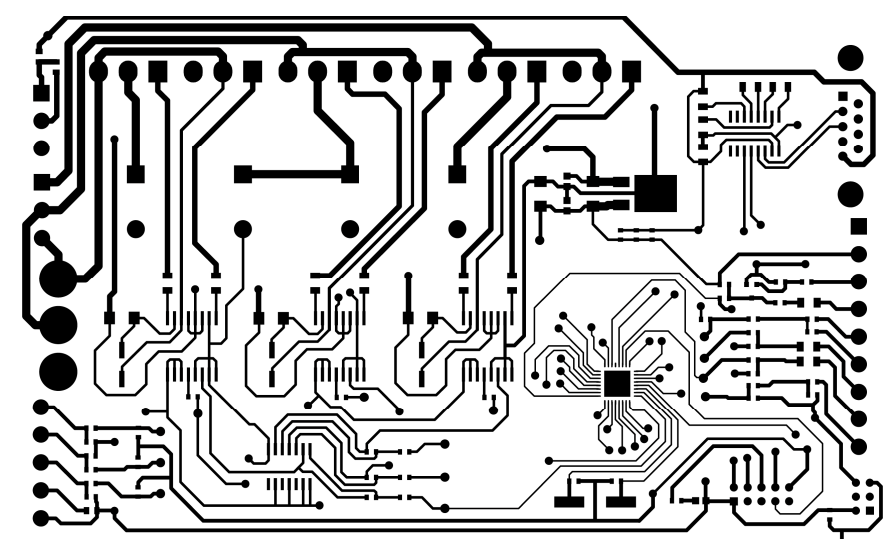

Fig. 5. Top layer gerber file of the BLDCM controller

When all components are placed in the right position, the PCB is introduced into a reflow oven to solder them. Finally, the through-hole components are soldered by hand and the PCB is placed in its enclosure (Fig. 6).

Because the 2-layer PCBs can be manufactured at the IUMA SFP Lab, the cost thereof is reduced, since you have only to spend on the materials and the components used. Moreover, these elements are commonly used and readily available. On the other hand, due to the modular design of the controller, it can be used in different applications. Thus, because of all these aspects, a low-cost BLDC motor controller is obtained.

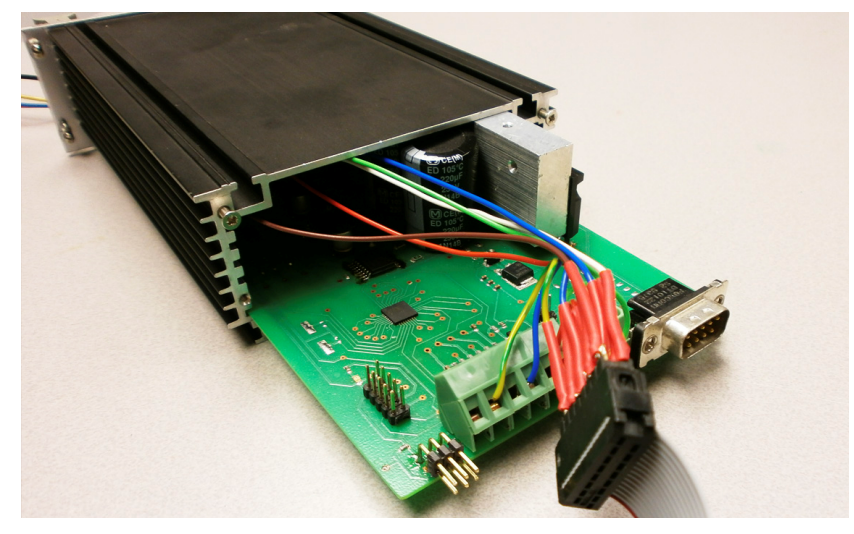

Fig. 6. Real view of the manufactured BLDCM controller

\section{THE TEST BENCH}

From the design of this low-cost controller, 3 possible applications in which integrate it have been developed.

\section{A. Basic control system}

This control system of BLDC motors is a learning kit designed and manufactured in order to be used to unify microcontroller programming practices with its direct application to control BLDC motors (Fig. 7). For this purpose, has been built a test bench where it is placed a BLDC motor mechanically connected to a conventional DC motor via a transmission belt. By this system, measurements of the motor torque can be taken applying a back electromotive force through the DC motor. On the side of the test bench, the external controls of the controller (the speed adjustment potentiometer, the motor rotation direction switch and the ignition switch) are located.

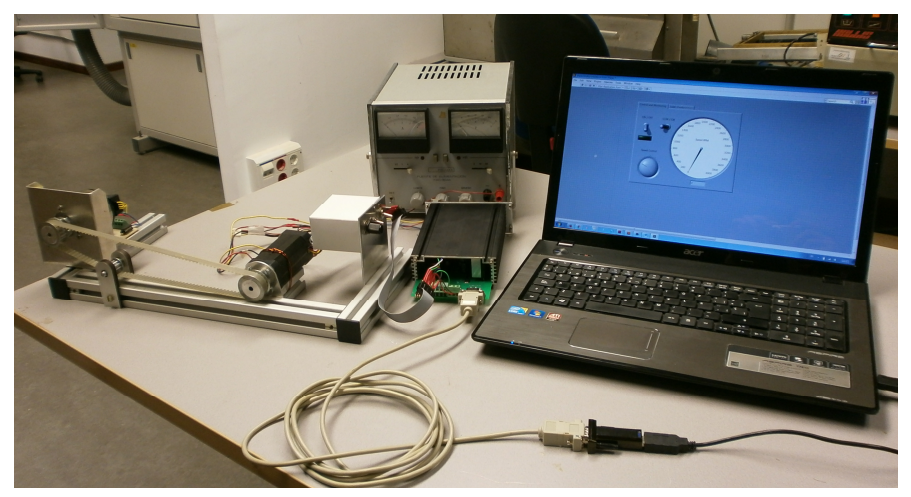

Fig. 7. View of the manufactured basic control system

Fig. 8 shows the interconnection of the elements of the control system for 3-phase BLDC motors. The motor sends the three Hall sensor signals to the controller, and this in turn sends the switching signals to the motor coils. These switching signals are sent with a duty cycle determined by the value of the speed adjustment potentiometer connected to the controller. In addition, there is an ignition switch that turns on the motor.

The controller and the motor are fed with a voltage of $24 \mathrm{~V}$ supplied by a Li-Ion battery pack which is managed by a BMS (Battery Management System). This analog BMS is part of another project developed by the IUMA [9]. The BMS monitor the state of a 7 cell battery pack (of $3.6 \mathrm{~V}$ each cell), ensuring the maximum durability thereof. In addition, it enables to make an accurate battery charging from a charger connected to the mains.

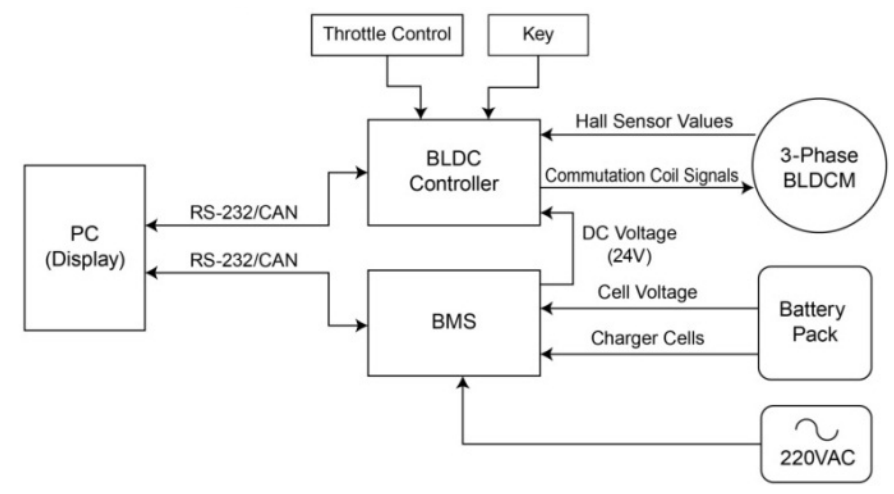

Fig. 8. Configuration of a basic BLDC motor control system

The controller and the BMS are connected to a workstation (PC) via serial under the RS-232 protocol. This communication, along with a program developed in LabView, allows monitoring the speed and the status of the motor, and the status of each cell in the battery pack.

In the proposed basic learning kit, the use of the battery pack and the BMS is optional. You can power the motor and the controller using a standard power supply that provides a 24 $\mathrm{V}$ of voltage and a minimum of $2 \mathrm{~A}$ of current to the motor 
used in the trials. The reference number of the BLDC motor used is 42BL100. Its main characteristics are shown in Table I.

TABLE I: 42BL100 BLDC MOTOR DATASHEET

\begin{tabular}{|l|c|}
\hline $\mathrm{N}^{\mathrm{o}}$ of Pole & 8 \\
\hline $\mathrm{N}^{\mathrm{o}}$ of Phase & 3 \\
\hline Rated Voltage $(\mathrm{V})$ & 24 \\
\hline Rated Speed $(\mathrm{rpm})$ & 4000 \\
\hline Rated Torque $(\mathrm{Nm})$ & 0,25 \\
\hline Max. Peak Torque $(\mathrm{Nm})$ & 0,75 \\
\hline Torque Constant $(\mathrm{Nm} / \mathrm{A})$ & 0,036 \\
\hline Max. Peak Current $(\mathrm{A})$ & 20 \\
\hline Mass $(\mathrm{kg})$ & 0,8 \\
\hline
\end{tabular}

\section{B. Control system for electric vehicles}

In this section, the configuration to perform a management system for electric vehicles is presented (Fig. 9). To make this system, two BLDC controllers are used with the goal of manage a 6-phase BLDC motor with a power of $5 \mathrm{~kW}$.

This kind of BLDC motor is used in electric motorcycles and it is managed by two independent controllers but synchronized with each other through external controls (the speed adjustment potentiometer and the ignition switch) and the Hall sensors from the motor. Each controller excites three of the six motor coils according to the order predetermined by the software and the Hall sensor signals.

The power supply of this system is a battery pack of $96 \mathrm{~V}$ ( 26 cells of $3.6 \mathrm{~V})$. The battery pack is managed by a BMS and both it and the two controllers are connected to a CAN bus. This protocol manages the communication between the boards and a display that shows the variables of the motor state and the battery pack. Furthermore, there is the possibility of connecting to the bus a computer for testing and monitoring the system.

With this control system, a prototype of a test bench applied to teaching in electromechanical practical sessions has been developed (Fig. 10). In this prototype the external controls have been replaced by software developed in LabVIEW, which enables the control of the motor from a PC.

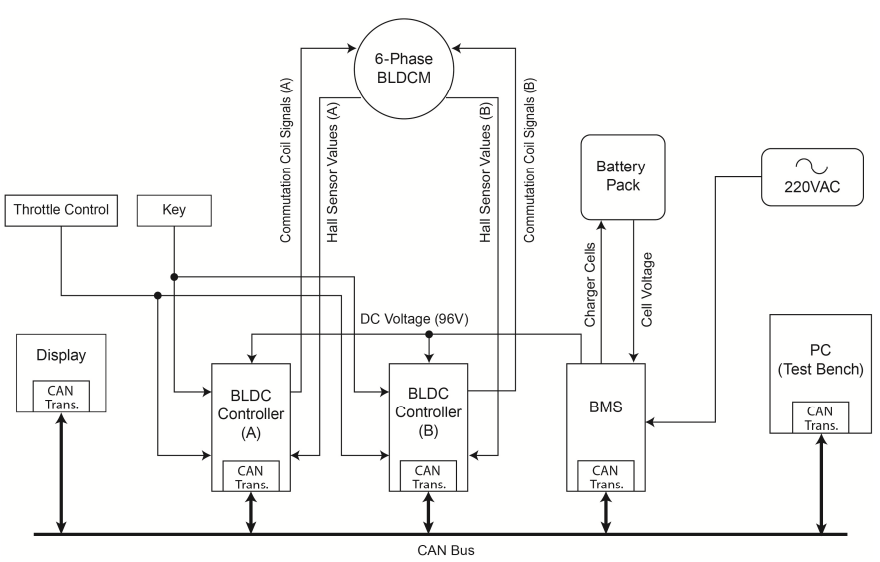

Fig. 9. Configuration of the control system for electric vehicles
It is noteworthy that it has been opened a new line of research to integrate the two controllers needed to control the 6-phase motors into a single controller. This controller has been specifically developed for use in motor management of electric motorcycles (Fig. 11).

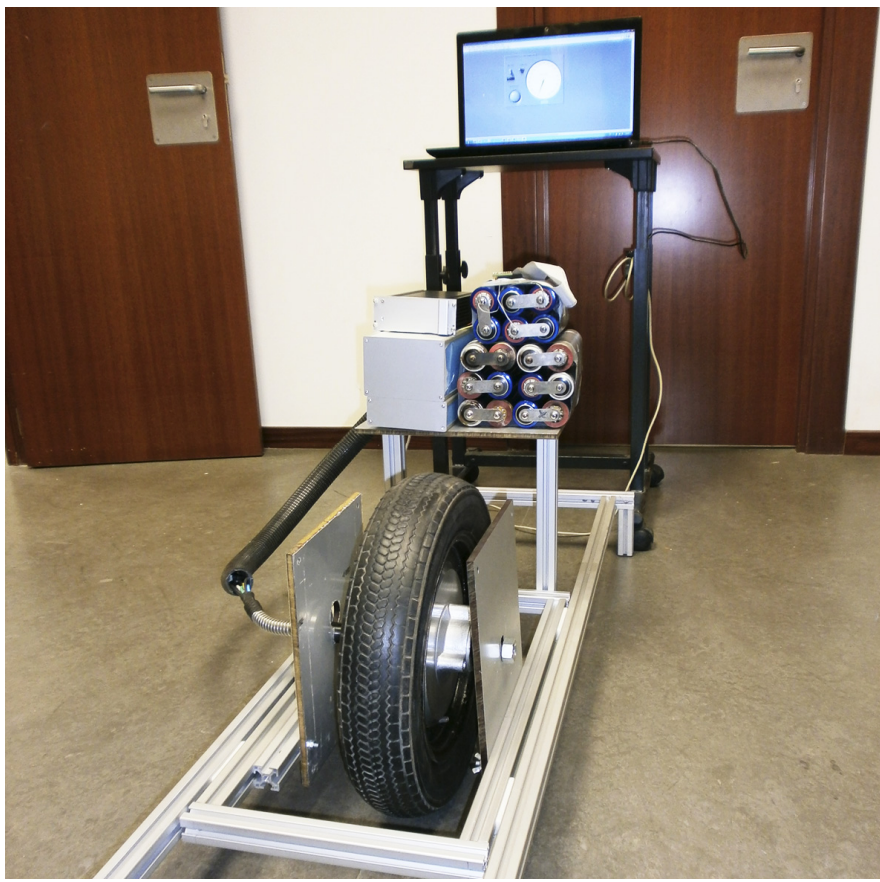

Fig. 10. View of the test bench of BLDCM control system for electric vehicles

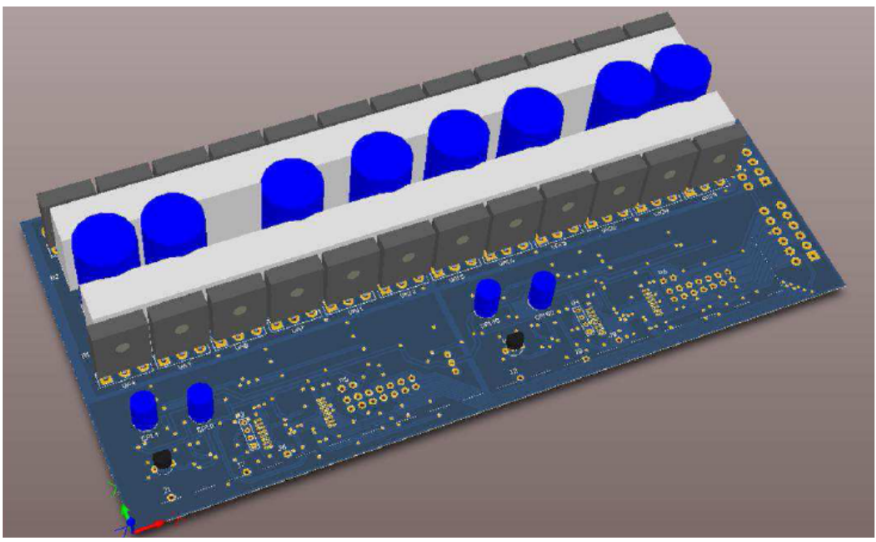

Fig. 11. 3D front view of the 6-phase BLDCM controller

\section{ROVs control system}

A project related to the ROVs, the AVORA project (Autonomous Vehicle for Operation and Research in Aquatic environments) is being currently developed in ULPGC by a team of students and researchers from this university in cooperation with PLOCAN (Canary Islands Oceanic Platform) [10]. The objective of the project is to design and manufacture electronics, mechanics and software of an autonomous underwater vehicle. With it the team will participate in the European competition SAUC-E 14 (Student Autonomous Underwater Vehicle Challenge - Europe), a prestigious event in the field of underwater robotics, which is annually held since 
2010 at the RSMC (Center for Maritime Research and experimentation) at Nato Underwater Research Center in $\mathrm{La}$ Spezia, Italy.

The propulsion system that is used by the AVORA ROV consists of four thruster DC motors with brushes. The control system of these motors is based on two control boards (RoboClaw Boards). Each one controls two motors. On the other hand, an Arduino Mega board controls the RoboClaw boards and communicates with the CPU (Central Processing Unit) via Ethernet. This CPU is connected via WIFI to the control station for receive the necessary commands when the robot is on the water surface (Fig. 12). When the robot is submerged, it will be completely autonomous.

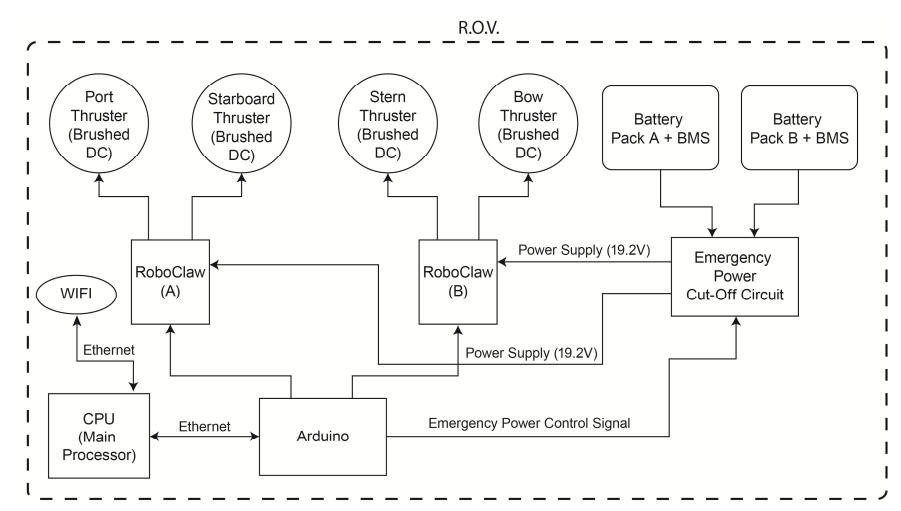

Fig. 12. Configuration of the current AVORA ROV control system

A future goal within this project is replacing the current propulsion system for a system based on BLDC motors. Thus, a greater efficiency of the vehicle, apart from the reduction in size and weight thereof, would be got. It is for this reason that we design a prototype of a ROV control system with BLDC motors based on the low-cost controller proposed in this paper.

This system is based on four 3-phase BLDC motors (Fig. 13). Each motor has a separate controller connected to a CAN bus. Also, as in the previous configurations, the system includes a battery pack that supplies the required voltage for the operation of the motors. This pack is managed by a BMS also connected to the CAN bus.

As in the current control system of ROV, a CPU is used to manage the system. The CPU will be integrated into the vehicle and it will receive the configuration commands via WIFI when it is in the water surface. In addition, the ability to control the ROV in real time using a remote control or PC will be implemented. This remote controller will be connected to the vehicle through an umbilical cable that will transmit data using the CAN protocol. The data transmission speed may vary between $500 \mathrm{kbps}$ and $10 \mathrm{kbps}$ according to the length of the cable used.

Another goal within this project in the future is redesigning the PCB controller to integrate these four independent controllers into a single control board for the four motors. Thus, a reduction in the size thereof would be obtained, and consequently, a decrease in size and weight of the vehicle.

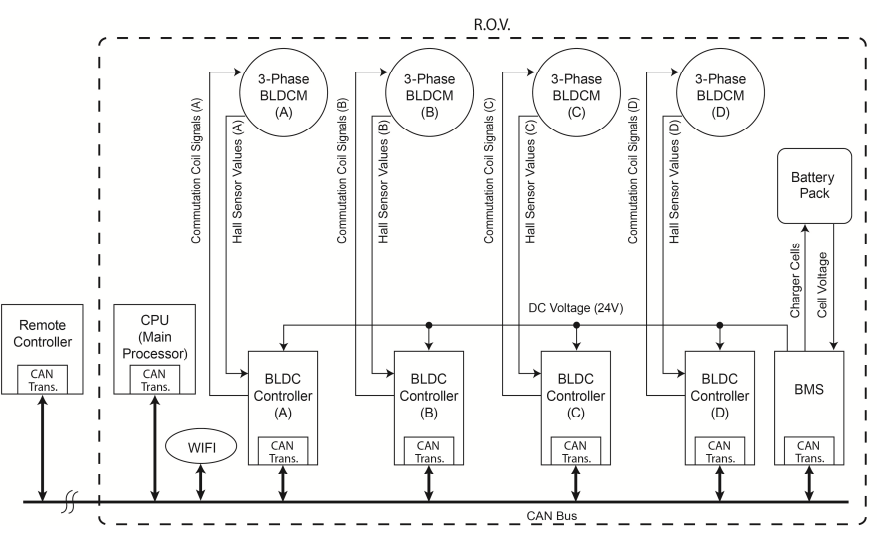

Fig. 13. ROV Control system with BLDC motors

\section{CONCLUSIONS}

The goal of this project is that students of electronics, electromechanical and robotic know both the software and hardware elements of a BLDC motors control system and their operation. By the use of the controller and test benches proposed in this paper, we believe that the teaching of this field can be successful and engaging for both the student and the teacher. Moreover, thanks to the RS-232 and CAN system connections, these control systems for teaching can be also used to teach the communication protocols.

At this moment, multiple controllers for use in practice at the next academic year 2014/2015 are being performed.

\section{REFERENCES}

[1] Atmel ATmega16/32/64M1 microcontroller's family: http://www.atmel.com/devices/ATMEGA64M1.aspx, Last accessed 2013, December.

[2] Wang Dongmei, Guo Haiyan, and Yu Jing, "Modeling and simulation research of brushless DC motor open-loop speed-adjustment system", The 2nd International Conference on Intelligent Control and Information Processing, ISBN 978-1-4577-0816-9, pp: 394 - 398, 2011.

[3] Alphonsa Roslin Paul, and Prof. Mary George, "Brushless DC motor control using digital PWM techniques", Proceedings of 2011 International Conference on Signal Processing, Communication, Computing and Networking Technologies (ICSCCN 2011), ISBN 9781-61284-653-8, pp: 733 - 738, 2011.

[4] K. R. Rajagopal, and Ajay Nair, "Design and development of a TMS320F2812 DSP controller based PM BLDC motor drive", International Conference on Electrical Machines and Systems (ICEMS), ISBN 978-1-4244-7720-3, pp: 776 - 780, 2010.

[5] H. A. Fabelo, A. Vega, J. M. Cabrera, and V. Déniz, "Librería C para el control de un motor BLDC basado en un Atmega64M1 para docencia", XI TAEE, 2014.

[6] Atmel Studio 6.0 Manual. [Online]. Available: http://atmel.no/webdoc/atmelstudio/, Last accessed 2013, December.

[7] Atmel AVRISP mkII microcontroller programmer: http://www.atmel.com/tools/avrispmkii.aspx, Last accessed 2013, December.

[8] Altium Designer Software: http://www.altium.com/en/products/altiumdesigner/overview, Last accessed 2013, December.

[9] V. Déniz, A. Vega, and J. M. Cabrera, "Diseño de un sistema de gestión de baterías Li-Ion", PFC, University of Las Palmas de Gran Canaria, 2013.

[10] A. Mahtani, L. Sanchez, A. Martínez, D. García, D. Morales, E. Fernandez, F. Maniscalco, and J. Cabrera, "AVORA I : The SAUC-E'12 challenge", The C Continuum, 2012. 